\title{
Design of intelligent university management services information platform based on large data
}

\author{
Liu Hao \\ National police university of ChinaLiaoning Shenyang110035 \\ This article is the phased research result of 2014 project of Liaoning \\ province education science "twelfth five-year" plan (JG14DB431).
}

\begin{abstract}
"Long-term education reform of the nation and development plan outline (2010-2020)" promulgated in July 2010,has put forward: "The information technology has revolutionary influence on the development of education, so it must be attached great importance to".With the rapid development of information technology, the, the construction of various university management for information and digital campus and wisdom campus has provided new means and rich resources for education teaching, also produced a large amount of data at the same time, and institutions of higher education are facing the challenge of big data. Combined with the demand of the service development in the college information, with realizing the intelligent information service as the goal, this paper has taken living examples to explain the data application service and decision support in the intelligent information management, and applied of key technologies such as ETL, data warehouse modeling to design intelligent information management service system of colleges and universities based on the technology of large data.
\end{abstract}

Key words: big data, colleges and universities, service, information

\section{Introduction}

Since 2012, the topic of "big data" began to fill in the media and from all walks of life.But compared to the influence of mobile Internet, cloud computing, network teaching, MOOC technology on the education industry, especially the influence of colleges and universities education information, the intelligent management service, etc,the influence of "big data" is also slightly insufficient. From the 1990s,universities across the country began information system construction in colleges and universities, covering the business of many facets of students, personnel, assets, etc.As the infiltration of social network in the life of learning, the demand of students, teachers and mid-level managers for information system service is no longer limited to the basic function such as the provided information, statistics data, and they produced higher expectationsto the services directly facing the consumers- intelligent information management 
service system of colleges and universities.On the one hand, colleges and universities have a large amount of historical data;On the other hand, data analysis based on the large data has made the realization of the intelligent service possible.Building intelligent information system in colleges and universities based on the technology of big data has extremely important significance to the intelligent management of day-to-day business in colleges and universities, intelligent recommendation of individuality demand of teachers and students to study and life.

\section{Content of smart university management services information platform}

1.1 Data extraction and integration. The experimental data in this paper, based on the data of students and teachers in national police university of China and Northeast University, with all kinds of information application system data platform in the school asthe support, data source includes both traditional and relational database and semi-structured XML data, and unstructured data existing in video, audio, text and other forms. The main problem that data extraction and integration want to solve is to collect various data of fragmentation, clean and conversethe data based on the ETL (Extraction-Transformation-Loading) technology, ensure the quality of data, at the same time constantly update data models according to the time evolution and determine the data entities and the relationship between them, will eventually store data in accordance with the unified format, in order to be provided for the upper to be used for data analysis.

1.2 Data analysis and the construction of data warehouse. Analyze the data by the extraction and integration and mineits potential value.Traditional data mining, machine learning and statistical analysis method can still be used to analyze the data, and can be adjusted according to the features of big data.According to Map/Reduce model we can implement the summary statistics analysis of huge amounts of data, and carry out resolution processing of the data, then summarizethe result;Apply of cloud computing platform to provide for big data analysis with computing resources security.Finally we can store the results of the analysis and establish the data warehouse.

1.3 Establish university intelligent management and service information system. Applying the above data analysis results and the data warehouse can develop and design university intelligent management and service information system.The system can automatically identify the user's explicit and implicit requirements, and provide active, efficient, safe, green services to meet their needs.Intelligence service is becoming a mainstream development direction afterinformation, is also the foundation of wisdom campus construction.The system mainly consists of the following function modules: employment situation analysis, personalized services recommendation, personalized learning guidance, forecasting and early warning, learning behavior analysis and decision support. 


\section{The employment situation analysis and module design route}

System mainly includes employment situation analysis, personalized services recommendation, personalized learning guidance, forecasting and early warning, learning behavior analysis and decision support six function modules. With the employment situation analysis module as example, the following briefly explains the technical route each module development and design adopts.Construction process of each module proceeds in accordance with the order: to determine the data source-data extraction-data analysis-data display.

2.1 Extracting information of the studentfrom all kinds of management system of colleges and universities shown in figure 1,constitutes all kinds of data the employment analysis model needs, and determines the source of data.

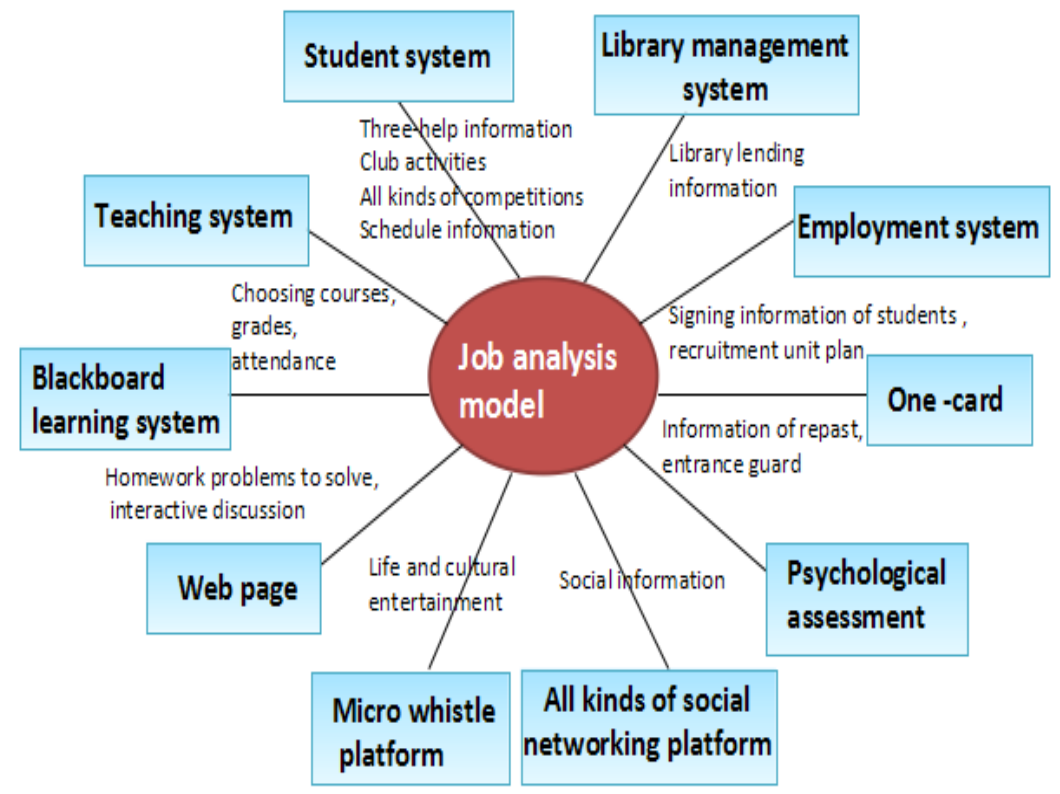

Figure 1 Employment module analysis model

2.2 In view of the different of data sources, we adopt different ways of data extraction, for universities information system data with good structure, we adopt the ETL tools such as Informatica Powercenter, Kettle to extract data to HBase database; For unstructured data, such as Web pages, we crawl it through Nutch, and index data and store to Hbase database through Solr, and the schematic diagram is shown in figure 2. 


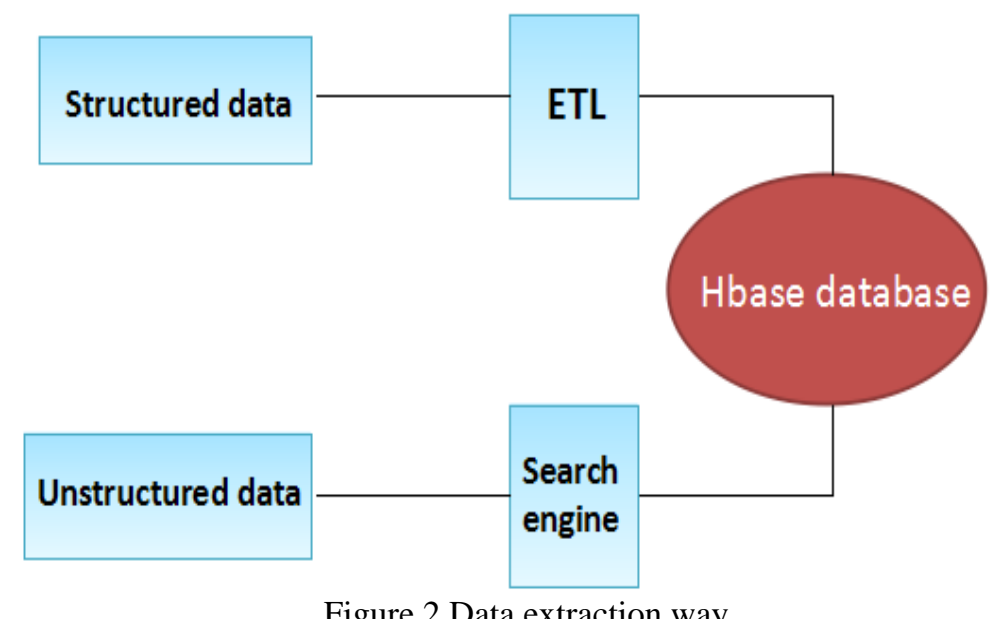

Figure 2 Data extraction way

2.3 After storing the data in Hbase database, using Hive to query and analyze the data in Hbase.Through the Hive to realize the summary statistics analysis of the employment data thattraditional data warehouse implemented.In addition to the data statistics and analysis, we can also use Mahout this machine to learn tool for supervised learning and unsupervised learning of data.In the job analysis, the first is collaborative filtering, this paper analyzes the achievement of students who have get a job, community activities they participated, concerned industry, personality characteristics, employment units and positions, etc., and calculates similarity between students, to recommend suitable employment units and posts for graduating students, and provides personalized services; The following is clustering, which is an unsupervised machine learning method, we can through the different dimensions analyze students who are failed to employ in time, and find their common characteristics, and then by comparing the relevant properties of students, timely given warning to the students, so that they can improve in the later study and life, as shown in figure 3.

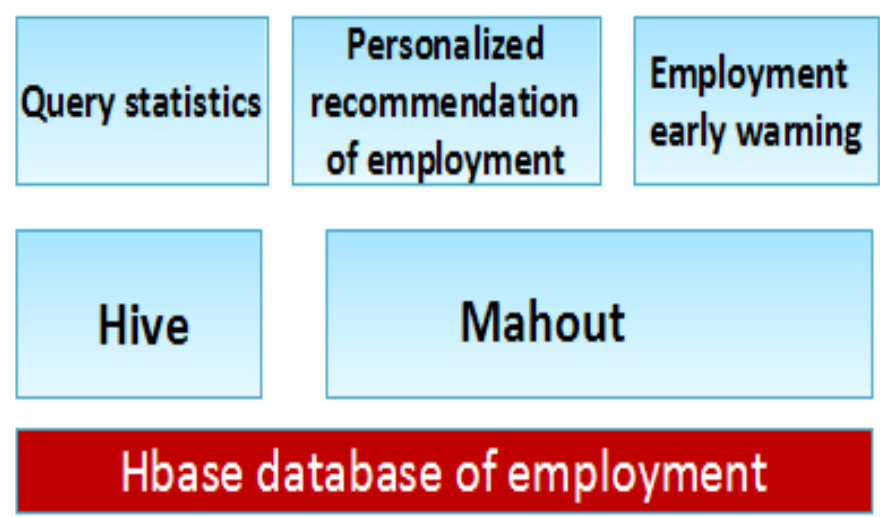

Figure 3 Employment data analysis

2.4 In the datadisplay layer, we can use the Tableau software to make visual presentation of analyzed results, and Tableau will combine datawith beautiful 
chart perfectly, which contains a huge number of predefined chart formats, at the same time can also display time, maps, etc multiple dimensions in a single chart.

\section{Module function introduction ofother businesses:}

3.1 Personalized services recommendation module: to clean and analyze the personal data, andprovide predictive and initiativeservice recommendation to customers.In the course system, for example, itwill provide course recommendations for the new course.After starting school, new students generally will be confused on what course to choose.For almost 10 years course data, we make analysis and cleaning up according to the same department, the same profession,and performance qualified rate dimensions, and list the students number of curriculum, and performance status information, then sort (for example, the top 10) to recommend new course.

3.2 Personalized learning guidance: the system, according to the major of the students, elective courses, online courses, hobbies and professional examination performanceinformation, intelligently pushes all kinds of learning reference materials.And through the network teaching platform, it can realize network learning and examination, etc.

3.3 Forecast warning service: when beginning the classes, teachers often have no accurate estimation to the proposed number of students who chose the course and had to adjust the classroom later.System can provide forecast quantity when teachers applied to the classroom, and try to avoid similar situation occurring.Through students' consumption record, class record, performance data, Internet record, and weibo, BBS information, it will make scientific storage and management of these data, and use big data technology for effective analysis and use, setting up the emotion model between teachers and students, which hasa great significance on mastering psychological health degree of teachers and students and making pointed reference to strengthen psychological guidance for teachers and students.

3.4 Learning behavior analysis: make analysis statistics for learning management system in colleges and universities, such as Blackboard, Sakai.These learning management systemsprovided course learning and communication spacefor students and teachers. The number of classes in the general colleges and universities every year is thousands, the student number in the tens of thousands, which are a large amount of data.Application of large data analysis technology makes each learning behavior to monitor student become possible, how long did it take students to answer a question, what problem is cleared, the research work to answer questions can be obtained, with the learning behaviors of students file creating adaptive learning system can improve the students' learning effects.

3.5 Decision support: provide dynamic multidimensional data information and background information about decision making for colleges and universities leadership, in addition to meeting the simple daily query, statisticsand maintenance, the global overall planning management, provide instantaneous 
change and development trend of the relevant education situation for policy makers in colleges and universities, extract the unknown in advance, potential, deep and valuable information implied in it.Such as scientific research and papers statistics analysis, the comprehensive analysis and comparison of student enrollment, special funds plan and finishing situation for teaching and scientific research, composition of teachers and annual analysis and comparison, etc.

\section{Conclusion}

Establishing university intelligent information management service system, making full use of the data, can change teaching and learning mode in the education field, realize the personalized learning, help the teaching management and the scientific calculation with huge amounts of data, and do the promotional activities of admissions, the degree management, early warning, decision support and so on.In this era where information is very precious, college teachers and students will get earnings from big data technology.

\section{References}

[1] Zhang Yixuan, Yu Yang. Big media in the era of big data[N]. People's Daily, 2013-01-17 (14).

[2] Viktor Mayer-Schönberger, Kenneth, etc. Big data[M]. Hangzhou: Zhejiang People's Publishing House, 2012.

[3] Lv Hong. College teaching quality evaluation research based on data mining technology [J]. Journal of Institute of Higher Education Research, 2007.

[4] Yao Hongyu, Tian Suning.Cloud computing: systems engineering of big data era, Beijing: Electronic Industry Press, 2013.

[5] Li Weiting.How to build a "wisdom police affairs" under the background of big data era, People's Public Security, 2012. 